\title{
ENHANCING CUSTOMER RETENTION IN RETAIL INDUSTRY
}

\author{
Avinash Somjani ${ }^{1}$ \\ ${ }^{l}$ Symbiosis Institute of Business Management (SIBM), Symbiosis International (Deemed University)(SIU), \\ Electronics City, Hosur Road, Bengaluru, Karnataka, India
}

\begin{abstract}
With the pandemic grabbing up places all over the world, the decline in businesses, macro and micro, is inevitable. Among these businesses is the retail sector which plays an important role for any economy. Retail sector covers all the basic necessities that a human being needs.
\end{abstract}

Retail sector is dependent on many factors that drive the sales of a company and the most vital one is the customer retention. With eruption of technology it is highly important to underscore the importance of social media and advanced technology. The main reason for that is the number of options the customers have. Due to this the switching cost is low. From the porter's analysis, we can clearly conclude that the bargaining power of the buyer is high for most retail commodities.

Many customers are loyal towards a brand because of the brand image, so it is highly important that a company fulfills its CSR programs in a way that can grab the attention of the customers and glue them to the brand. This brand image can also be connected to the store ambience.

This study is based on various factors that are perceived by the customers as of value and how these factors can enhance the customer retention.

Keyword: Customer Retention, Customer Satisfaction, CSR, Sales Promotions, Technology Advancement, Social Media Marketing, Store Ambience.

\section{Introduction}

From the barter system to the floating currency that we trade around these days, the retail industry has always been on the rise due to the large scope of products that it covers and basic needs that it fulfills. This has given a rise in the competition and has painted almost everything red. The customers have innumerable choices with the e-commerce industry penetrating many markets of the retail industry. Switching costs for the customers are decreasing drastically and the players are finding it hard to retain the good customers (Mittal, V. (2013)'Customer Satisfaction: A Strategic Review and Guidelines for Managers', SSRN).

It is very important for companies to retain their customers as it is one of the most efficient ways for good organisational performance and competitiveness. Customer retention is basically the ability of the company to retain the customers that bought a product from the company. Customers come back for a product only if they see value. The companies are supposed to find this value aspect of a potential trade and work towards it so that they can retain the customer.

Walmart did it with its everyday low pricing, McDonalds did it with its speedy service and high quality burgers and Apple did it with its spectacular brand image. These companies took no time in understanding the importance of positive customer experience to pursue customer retention. In order to respond to this tough competition, it is vital to identify and understand the drivers of customer retention. Previous research has been on the scope larger than the retail industry and it couldn't be generalised for all industries.

Retailers need to pack up their strengths and try to differentiate themselves from the red ocean in order to be perceived as a company with great value propositions. They also need to gain an understanding of the buying behaviour of these customers and do their bidding for the goods and services that can satisfy their needs(Khadka, K. (2017) 'Customer satisfaction and customer loyalty',Core). It will surely help the retailers form a formidable brand image which will keep the customers loyal to the retailers.

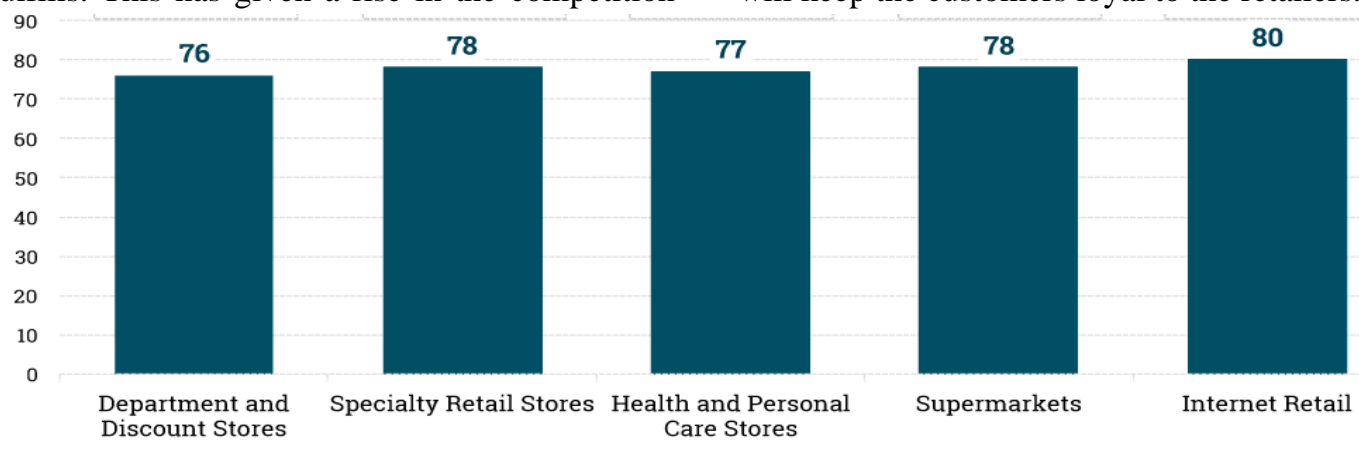

Source: The American Customer Satisfaction Index 
The chart above shows the customer satisfaction of the American People at 100 point rating keeping all kinds of retail stores in the study and there is clearly room for improvement. The chart below shows the market size of the Indian retail sector. The retail sector is filled with vendors and its mostly red ocean but with this red ocean, the market size is increasing every year. This is a great opportunity for retailers to take on this rising tide of retail in 2020(The American Customer Satisfaction Index).

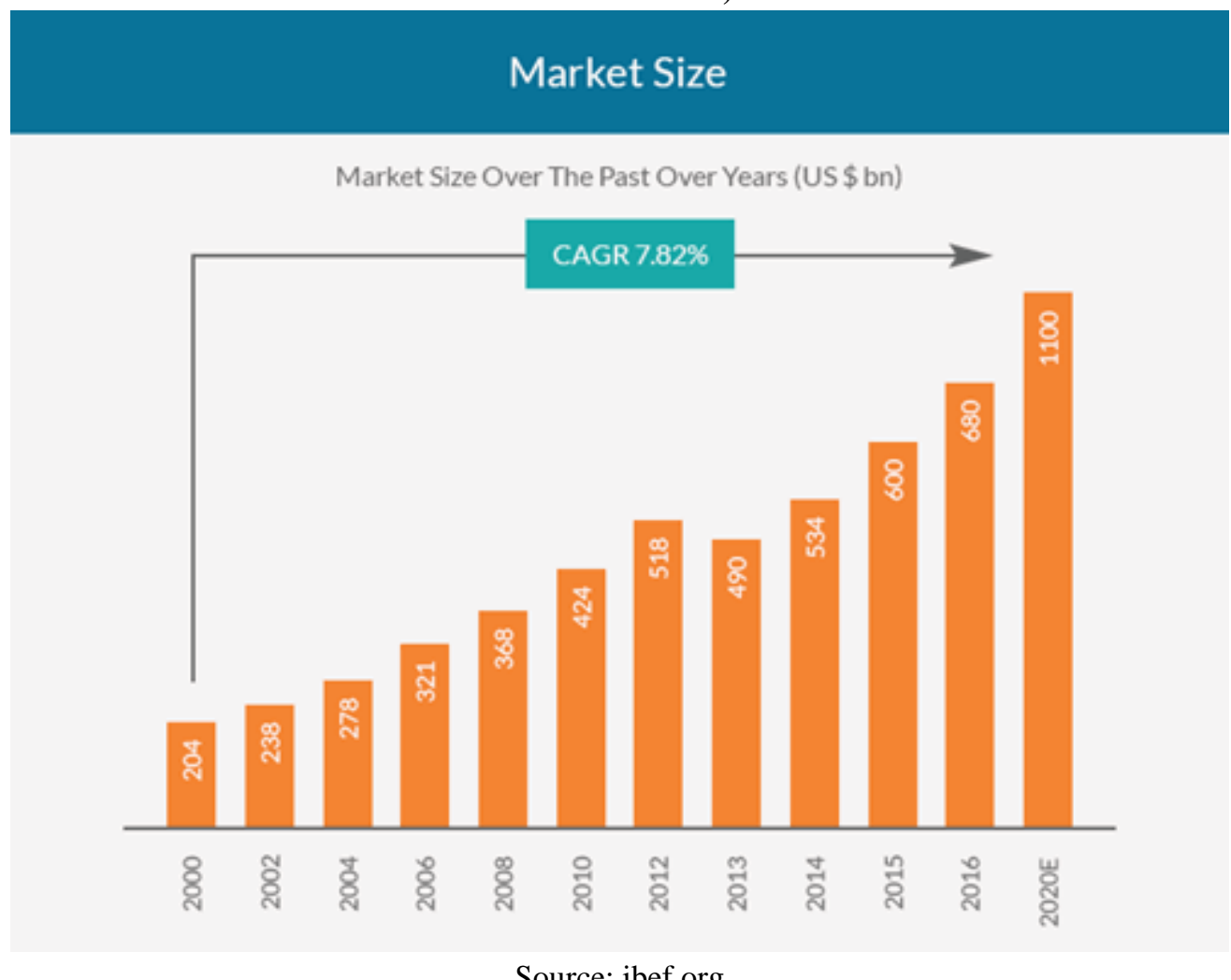

Previous research has restricted its scope to promotions and pricing, while the effect of social media was either nonexistent in those times or written off. Social Media marketing is on the rise and it is affecting the buying behaviour of the customers in a very unprecedented way. Retail businesses are getting cleaner, leaner and smarter. This study will cover all these factors without discounting anything that has an impact on customer retention in the retail industry. This can help retailers focus on just the right things and be more effective.

\section{Literature Review}

\section{The Value for Consumer in Retail,}

According to Cavalcante,B. Ikeda,A. (2015), Brazilian Business Review ,the retailers should come up with ways to making the shopping process more engaging and of more value. The objective is to know what the customers value while shopping. This research increases understanding of what is valued in a holistic shopping experience by a customer and also gives a perspective to toy retailers on how to find the points in their service or goods that provide value to the customer.

\section{Perceived Value in Retail}

According to Molina,M. Saura,I. (2008), Journal of Retail and Leisure Property, what is perceived of value by a customer is totally subjective, since it evaluates the entire product according to his/her need. The value perceived by a

customer is of various components and combined as one, it has significance of further scope. The paper has also shown the relationship between perceived value and customer attitude and how it can alter the buying behaviour. This paper studies the influence of various components of perceived value on many retail components.

\section{Customer Retention}

According to Weinstein,A. (2010) , Journal of targeting Measurement and Analysis, companies need to finalise a model to enhance customer retention and also take actions to increase long-term customer relationships. It mirrors the importance of customer retention. It can help make an integrated customer retention model and can also explain how usage segmentation can assist in relationship-building and increasing profits.

\section{The Meaning and Measurement of Customer Retention}

According to Aspinall,E. Nancarrow,C. (2001), Journal of Targeting, Measurement and Analysis, companies are in dire need to increase their emphasis on customer retention. It also determines the extent to which organisations have agreed clear definitions of what constitutes customer retention and also shows various measurement instruments like trends, sales, loyalty, commitment, feedback and response to activity.

\section{Behavioral Perspectives of Customer Engagement}

According to Javornik,A. Mandelli,A. (2012) , Database 
Mark brand image as their competitive advantage, it is important for

eting and Customer Strategy Management, the phenomenon of engaging customers and defining it with various aspects, is of utmost importance to retailers if they are strategizing a long • term goal. It discusses different angles of customer engagement and aims to provide an area within which the terms can further be worked upon.

Customer Value and Value for Customer - The Need for॰ Transformation

According to Mau,N. (2013), Journal of Marketing Research and Case Studies, The paper talks about various trends in the $\bullet$ competition and online trends to figure out new ways of customer involvement. It also determines the effect of price sensitivity on perceived value by the customer. This paper focuses on the Point of Sale in stationary retail in the context to consumer-packaged goods.

\section{Store Choice In The Indian Apparel Retail Market}

According to Mittal,A. (2008), IBSUSJ, the retail sector in India has been fragmented and unorganised and how western retailers have entered the scene with store location all over the country. But these retailers have only put their western stores on Indian lands without studying various store attributes from a customer perspective. The purpose has been to study the store choice criteria in the context of the apparel industry in India. The paper has identified "loyalty drivers" and "experience enhancers" as key dimensions, which in different combinations enhances the choices of store locations.

\section{Customer Satisfaction in the Retail Market}

According to Mattsson,K. (2009), SSRN, this paper relies on how the Gant stores in Helsinki can strategize ways to enhance customer satisfaction, the merchandising options and• ambience at the stores. The company had never carried out such a survey and hence they had no idea about what their customers see of value. The author points out various gaps in company's value proposition and tries to fill those voids after using the survey analysis.

\section{Retail Store Preference and in-Store Digitization}

According to Saha,S. Sharma,A. Kumar,A. (2019), , International Journal of Recent Technology and Engineering, the objective of the research was to study the factors that influence retail store preference. It also studies if the in-store digitization has any impact on store preference. For factor analysis, the author used modernization, convenience, advanced technology and virtual reality. The paper concluded that the factor will dramatically affect the store preference.

\section{The Role of Store Image in Retail Internationalisation}

According to Burt,S. (2006), Institute of Retail Studies, the role of store image in the retail's internationalisation process is important as the brand image of the company is reflected directly from it. The retailers in the domestic market making them to take this advantage to international markets.

Research Gap

The perceived value and the expectations of the retailer and the customers are not aligned.

Previous research hasn't considered social media marketing as an important variable when it comes to customer retention.

Customer perception and perceived value about the company with regard to its humanitarian work and corporate social responsibility has been discounted many times.

Effects of store facilities, in-store technology and the retailer's website features on customer retention is evolving everyday and previous knowledge is not sufficient to understand the current scenario.

Objectives

- To study the factors that affect the perception of value by a customer in the retail sector.

Every customer values different factors in a different way. This calls for an action to get the broad overview of how these factors are valued by customers in a particular demographic. There will be nine independent variables tested against one dependent variable.

To apply these factors in strategy making of enhancing customer retention.

After the correlational analysis, the results will show which factors to be considered in the strategy making of a company.

Scope of the Research

- The findings from this research will provide valuable information to the retailers which will enable them to alter their strategies for customer retention.

It will enable the retailers to find the factors which are valued by the customer and hence, the retailers can improve their product in accordance to the findings.

Data And Methodology

A quantitative approach will be used for the research. The data collection will be primary and will be carried out using a questionnaire. Convenience sampling has been used in the data collection process to ensure the randomness in the data.

The objectives of the research were clearly explained. Before data collection took place, the questionnaire which comprised of the items about respondents' profile and research constructs were designed.

After the data collection process, all the independent variables will be correlated to the dependent variable i.e. Customer Retention. With the data being non-normal, the alternative of Pearson's correlation coefficient, Spearman's rank correlation coefficient is used.

Hypothesis

$\mathrm{H}_{\mathrm{o}}$ : There is no correlation between customer retention(dependent variable) and the independent variables.

$\mathrm{H}_{1}$ : There is correlation between Customer retention and Social Media Marketing. 
$\mathrm{H}_{2}$ : $\mathrm{H}_{7}$ : There is correlation between Customer retention and

There is correlation between Customer retention and Sales Promotion.

$\mathrm{H}_{3}$ : There is correlation between Customer retention and Corporate Social Responsibility.

$\mathrm{H}_{4}$ : There is correlation between Customer retention and InStore Digitization

$\mathrm{H}_{5}$ : There is correlation between Customer retention and Customer Service

$\mathrm{H}_{6}$ : There is correlation between Customer retention and Store Location.
Merchandise Options.

$\mathrm{H}_{8}$ : There is correlation between Customer retention and Store Ambience.

$\mathrm{H}_{9}$ : There is correlation between Customer retention and Technology Advancements (Website, Apps for Delivery)

Data Analysis

\section{1] Gender}

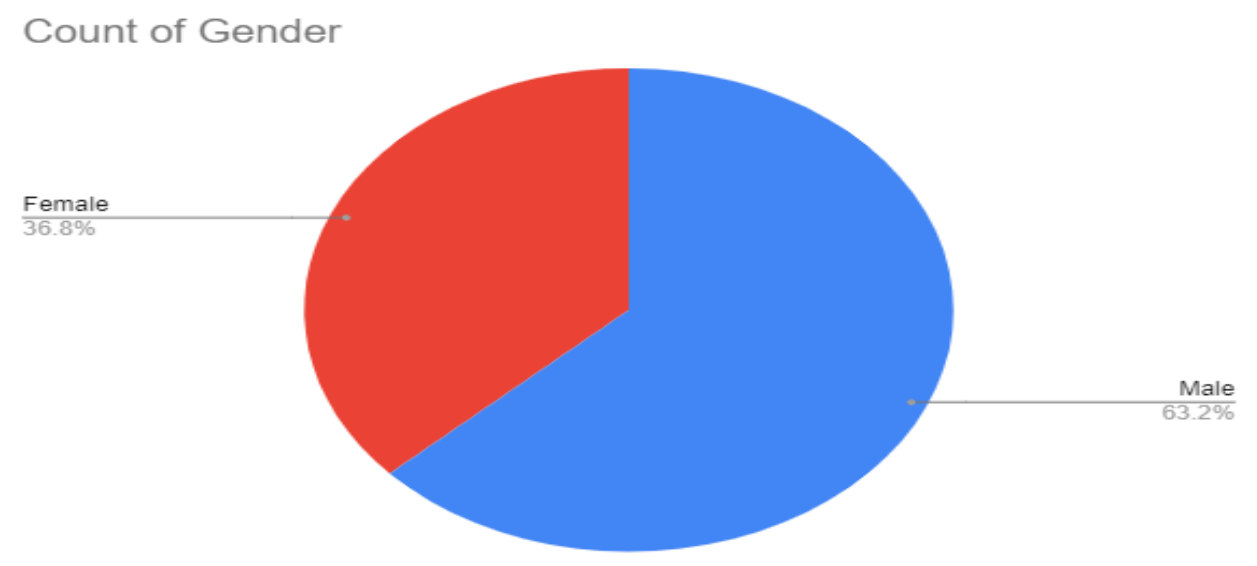

2] Age Groups

It was found that out of 95 respondents, 60 of them were male and 35 of them were female.

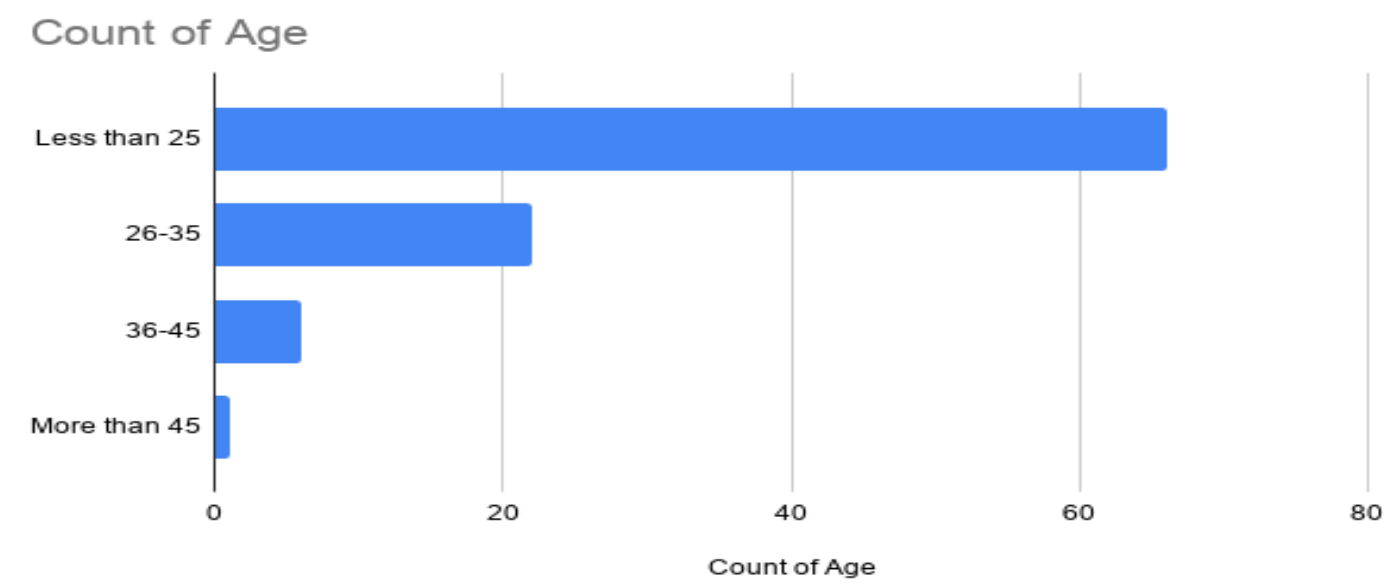

On segregating various respondents into age categories, it was found that 66 of the respondents were aged less than 25 years, 22 of the respondents were aged between 26 years -35 years, 6 of the respondents were aged between 36 years -45 years and only one of the respondents was aged more than 35 . This suggests that the research is based on the perception of the Generation $\mathrm{Z}$ and the Millenials.

\section{3] Chi Squared test of Independence}

To check the independence of variables, Chi-squared test was calculated comparing the social media marketing and sales promotions. An insignificant interaction was found $\left(\chi^{2}(1)=\right.$
$9.98,0.505>0.05)$. These variables are independent from each other.

To check the independence of variables, Chi-squared test was calculated comparing the social media marketing and corporate social responsibilities. An insignificant interaction was found $\left(\chi^{2}(1)=15.5,0.201>0.05\right)$. These variables are independent from each other.

To check the independence of variables, Chi-squared test was calculated comparing the social media marketing and in store digitization. An insignificant interaction was found $\left(\chi^{2}(1)=\right.$ $8.3,0.31>0.05)$. These variables are independent from each other. 
To

check the independence of variables, Chi-squared test was calculated comparing the social media marketing and customer service. An insignificant interaction was found $\left(\chi^{2}(1)=14.6\right.$, $0.4>0.05)$. These variables are independent from each other.

To check the independence of variables, Chi-squared test was calculated comparing the social media marketing and store location. An insignificant interaction was found $\left(\chi^{2}(1)=7.21\right.$, $0.102>0.05)$. These variables are independent from each other.

To check the independence of variables, Chi-squared test was calculated comparing the social media marketing and merchandise options. An insignificant interaction was found $\left(\chi^{2}(1)=13.25,0.651>0.05\right)$. These variables are independent from each other.

To check the independence of variables, Chi-squared test was calculated comparing the social media marketing and technology advancement. An insignificant interaction was found $\left(\chi^{2}(1)=9.25,0.3>0.05\right)$. These variables are independent from each other.

To check the independence of variables, Chi-squared test was calculated comparing the social media marketing and store ambience. An insignificant interaction was found $\left(\chi^{2}(1)=\right.$ $12.3,0.51>0.05)$. These variables are independent from each other.

To check the independence of variables, Chi-squared test was calculated comparing the sales promotions and corporate social responsibility. An insignificant interaction was found $\left(\chi^{2}(1)=15.24,0.228>0.05\right)$. These variables are independent from each other.

To check the independence of variables, Chi-squared test was calculated comparing the sales promotions and in store digitization. An insignificant interaction was found $\left(\chi^{2}(1)=\right.$ $10.038,0.347>0.05)$. These variables are independent from each other.

To check the independence of variables, Chi-squared test was calculated comparing the sales promotions and customer service. An insignificant interaction was found $\left(\chi^{2}(1)=\right.$ $11.321,0.421>0.05)$. These variables are independent from each other.

To check the independence of variables, Chi-squared test was calculated comparing the sales promotions and merchandise options. An insignificant interaction was found $\left(\chi^{2}(1)=\right.$ $14.26,0.259>0.05)$. These variables are independent from each other.

To check the independence of variables, Chi-squared test was calculated comparing the sales promotions and store ambience. An insignificant interaction was found $\left(\chi^{2}(1)=\right.$ $9.250,0.681>0.05)$. These variables are independent from each other.

To check the independence of variables, Chi-squared test was calculated comparing the sales promotions and corporate social responsibility. An insignificant interaction was found $\left(\chi^{2}(1)=13.258,0.148>0.05\right)$. These variables are independent from each other.

To check the independence of variables, Chi-squared test was calculated comparing the corporate social responsibilities and customer service. An insignificant interaction was found $\left(\chi^{2}\right.$ $(1)=9.67,0.645>0.05)$. These variables are independent from each other.

To check the independence of variables, Chi-squared test was calculated comparing the corporate social responsibilities and in store digitization. An insignificant interaction was found $\left(\chi^{2}\right.$ $(1)=5.918,0.918>0.05)$. These variables are independent from each other.

To check the independence of variables, Chi-squared test was calculated comparing the corporate social responsibilities and store location. An insignificant interaction was found $\left(\chi^{2}(1)=\right.$ $14.32,0.245>0.05)$. These variables are independent from each other.

To check the independence of variables, Chi-squared test was calculated comparing the corporate social responsibilities and merchandise options . An insignificant interaction was found $\left(\chi^{2}(1)=8.583,0.983>0.05\right)$. These variables are independent from each other.

To check the independence of variables, Chi-squared test was calculated comparing the corporate social responsibilities and technology advancement. An insignificant interaction was found $\left(\chi^{2}(1)=11.25,0.741>0.05\right)$. These variables are independent from each other.

To check the independence of variables, Chi-squared test was calculated comparing the corporate social responsibilities and store ambience. An insignificant interaction was found $\left(\chi^{2}(1)\right.$ $=21.21,0.3>0.05)$. These variables are independent from each other.

To check the independence of variables, Chi-squared test was calculated comparing the customer service and in store digitization. An insignificant interaction was found $\left(\chi^{2}(1)=\right.$ $13.41,0.21>0.05)$. These variables are independent from each other.

To check the independence of variables, Chi-squared test was calculated comparing the customer service and store location. An insignificant interaction was found $\left(\chi^{2}(1)=11.36,0.11>\right.$ $0.05)$. These variables are independent from each other.

To check the independence of variables, Chi-squared test was calculated comparing the customer service and store ambience. An insignificant interaction was found $\left(\chi^{2}(1)=\right.$ $11.87,0.447>0.05)$. These variables are independent from each other.

To check the independence of variables, Chi-squared test was calculated comparing the customer service and merchandise options . An insignificant interaction was found $\left(\chi^{2}(1)=\right.$ $17.32,0.78>0.05)$. These variables are independent from each other.

To check the independence of variables, Chi-squared test was calculated comparing the customer service and technology 
advan cement. An insignificant interaction was found $\left(\chi^{2}(1)=8.14\right.$, $0.238>0.05)$. These variables are independent from each other.

To check the independence of variables, Chi-squared test was calculated comparing the in store digitization and store location.

An insignificant interaction was found $\left(\chi^{2}(1)=5.06,0.871>\right.$ $0.05)$. These variables are independent from each other.

To check the independence of variables, Chi-squared test was calculated comparing the in store digitization and merchandise options. An insignificant interaction was found $\left(\chi^{2}(1)=\right.$ $10.517,0.571>0.05)$. These variables are independent from each other.

To check the independence of variables, Chi-squared test was calculated comparing the in store digitization and store ambience. An insignificant interaction was found $\left(\chi^{2}(1)=\right.$ $5.87,0.132>0.05)$. These variables are independent from each other.

To check the independence of variables, Chi-squared test was calculated comparing the in store digitization and technology advancement. An insignificant interaction was found $\left(\chi^{2}(1)=\right.$ $7.991,0.595>0.05)$. These variables are independent from each other.

To check the independence of variables, Chi-squared test was calculated comparing the store location and merchandise options. An insignificant interaction was found $\left(\chi^{2}(1)=\right.$ $5.249,0.949>0.05)$. These variables are independent from each other.

To check the independence of variables, Chi-squared test was calculated comparing the store location and store ambience. An insignificant interaction was found $\left(\chi^{2}(1)=14.207,0.248\right.$ $>0.05)$. These variables are independent from each other.

To check the independence of variables, Chi-squared test was calculated comparing the store location and technology advancement. An insignificant interaction was found $\left(\chi^{2}(1)=\right.$ $9.9,0.359>0.05)$. These variables are independent from each other.

To check the independence of variables, Chi-squared test was calculated comparing the store ambience and merchandise options. An insignificant interaction was found $\left(\chi^{2}(1)=\right.$ $10.329,0.838>0.05)$. These variables are independent from each other.

To check the independence of variables, Chi-squared test was calculated comparing the store ambience and technology advancement. An insignificant interaction was found $\left(\chi^{2}(1)=\right.$ $14.385,0.103>0.05)$. These variables are independent from $\bullet$ each other.

To check the independence of variables, Chi-squared test was $\bullet$ calculated comparing the technology advancement and $\bullet$ merchandise options. An insignificant interaction was found $\bullet$ $\left(\chi^{2}(1)=7.29,0.788>0.05\right)$. These variables are independent $\bullet$ from each other.

\section{Spearman's Correlation Test}

The impact of social media marketing, sales promotions, corporate social responsibility, in store digitization, customer service, store location, merchandise options, store ambience and technology advancement on the retailer's customer retention was tested with Spearman's correlation test.

\section{4] Social Media Marketing}

Based on the results of the study, customers tend to buy again from the retailer with active social media marketing. $\boldsymbol{r}_{\boldsymbol{s}}=$ $0.354, p<0.05$

\section{5] Sales Promotion}

Based on the results of the study, customers tend to buy again from the retailer with sales promotions. $\boldsymbol{r}_{s}=\mathbf{0 . 7 0 3}, \boldsymbol{p}<\mathbf{0 . 0 5}$

\section{5] Corporate Social Responsibility}

Based on the results of the study, customers tend to buy again from the retailer who fulfills his corporate social responsibilities.. $\boldsymbol{r}_{\boldsymbol{s}}=\mathbf{0 . 3 4 6}, \boldsymbol{p}<\mathbf{0 . 0 5}$

\section{6] In-Store Digitization}

Based on the results of the study, there is no credible evidence that the customer will buy again from the retailer considering his in store digitization. $\boldsymbol{r}_{\boldsymbol{s}}=\mathbf{- \mathbf { 0 . 0 1 } , \boldsymbol { p } > \mathbf { 0 . 0 5 }}$

\section{7] Customer Service}

Based on the results of the study, customers tend to buy again from the retailer with efficient customer service. $\boldsymbol{r}_{\boldsymbol{s}}=\mathbf{0 . 7 2 6}$ $p<0.05$

\section{8] Store Location}

Based on the results of the study, there is no credible evidence that the customer will buy again from the retailer considering his store location. $\boldsymbol{r}_{\boldsymbol{s}}=\mathbf{0 . 1 9 6}, \boldsymbol{p}>\mathbf{0 . 0 5}$

\section{9] Merchandise Options}

Based on the results of the study, customers tend to buy again from the retailer with wider merchandise options. . $\boldsymbol{r}_{\boldsymbol{s}} \mathbf{=} \mathbf{0 . 4 5 4}$, $p<0.05$

\section{0] Store Ambience}

Based on the results of the study, there is no credible evidence that customers will buy again from the retailer considering his store ambience. $\boldsymbol{r}_{\boldsymbol{s}}=\mathbf{0 . 1 7 4}, \boldsymbol{p}>\mathbf{0 . 0 5}$

\section{1] Technology Advancement}

Based on the results of the study, customers tend to buy again from the retailer with technology advancement. $\boldsymbol{r}_{\boldsymbol{s}}=\mathbf{0 . 3 4 5}$, $p<0.05$

Findings and Conclusions

$\mathrm{H}_{1}:$ We fail to reject it as $\mathrm{p}<0.05$

$\mathrm{H}_{2}$ : We fail to reject it as $\mathrm{p}<0.05$

$\mathrm{H}_{3}$ : We fail to reject it as $\mathrm{p}<0.05$

$\mathrm{H}_{4}$ : We reject it as $\mathrm{p}>0.05$

$\mathrm{H}_{5}$ : We fail to reject it as $\mathrm{p}<0.05$

$\mathrm{H}_{6}$ : We reject it as $\mathrm{p}>0.05$

$\mathrm{H}_{7}$ : We fail to reject it as $\mathrm{p}<0.05$

$\mathrm{H}_{8}$ : We reject it as $\mathrm{p}>0.05$ 
We fail to reject it as $\mathrm{p}<0.05$

- Social Media marketing, sales promotions, corporate social responsibility, customer service, merchandise options and technology advancement have a significant relationship with customer retention and correlate positively at 5\% significance level. There is sufficient evidence to reject the claim that there is no correlation between the above stated variables and customer retention.

- This indicates that if retailers can work effectively on social media marketing, sales promotions, CSR activities, customer service, merchandise options and technology advancement, they can enhance their customer retention rates.

- In Store digitization, Store location and Store ambience have a non-significant relationship with customer retention at $5 \%$ significance level. There is no sufficient evidence to reject the claim that there is no correlation between the above stated variables and customer retention.

1] With the majority of the respondents being Generation $Z$ and Millenials, it was expected that the correlation between customer retention and technology related factors like social media marketing and technology advancement would be positive. However, it was surprising that in-store digitization correlated negatively with customer retention. The New Puma Store in Indiranagar, Bangalore has high in-store digitization facilities and it is rated very high.

2] Factors like Technology Advancement, Corporate Social Responsibility, Sales Promotions, Social Media Marketing, Merchandise Options and Customer Service have correlated positively. This shows that while making strategies for a retail company, the management should focus on these positively correlated factors.

3] It can be concluded that customer retention can be enhanced through following tactics.

- Amp up social media campaigns

- Provide minimalistic websites and applications for deliveries.

- Popular CSR activities

- Varied merchandise options

- Doing sales promotions

- Excellent customer service

\section{Limitations}

The research is based on the participants in India. The findings and conclusions may vary in other countries. Age group was limited to Gen $\mathrm{Z}$ and Millennials. Different age groups may behave differently in the same situations.

Scope of Future Research

The research conducted has only achieved to study the perceptions of Gen $\mathrm{Z}$ and Millennials. Future research can study different age groups and in this case, people of different countries. Future research can focus on different demography and different country contexts. A bigger sample size can also be incorporated.

It can also test other factors, such as distribution intensity and price. There is scope to test the variables with qualitative methods. Unstructured questions and focus groups can provide new insights.

\section{References}

[1]. McDougall, G. (2001) 'Customer retention strategies: When do they pay off?', Services Marketing Quarterly.

[2]. Lee, Y. Hsieh,y. (2016) 'An empirical research on customer satisfaction study: a consideration of different levels of performance', Springer

[3]. Khadka, K. (2017) 'Customer satisfaction and customer loyalty',Core.

[4]. Palm, P. ( 2016)'Measuring Customer Satisfaction: A Study of the Swedish Commercial Real Estate Industry', Diva Portal

[5]. Mittal, V. (2013)'Customer Satisfaction: A Strategic Review and Guidelines for Managers', SSRN

[6]. Gupta, G. (2016)' Evaluation of Indian Retail Market', Academia 